\title{
LA TRAGEDIA DEL PRÍNCIPE. EL PROBLEMA DE LA RAZÓN DE ESTADO Y SU RELACIÓN CON EL CONFLICTO POLÍTICO EN MAQUIAVELO
}

\begin{abstract}
Cecilia Mc Donnell *
En el presente trabajo se analizará si es posible hablar de una teorización por parte de Maquiavelo del problema de la razón de Estado, contra aquellas interpretaciones que parten de tal problema con vistas a hacer una lectura tecnocrática. Se considerará tal concepto desde una clave interpretativa trágica, que nos permitirá explorar el pensamiento maquiaveliano en tanto atravesado por el conflicto, lo cual torna imposible reducirlo a un mero cálculo de medios y fines.
\end{abstract}

Palabras clave: Maquiavelo, Schmitt, conflicto, razón de Estado, tragedia.

\section{THE TRAGEDY OF THE PRINCE. THE RELATIONSHIP BETWEEN THE} PROBLEM OF RAISON D'ÉTAT AND THE POLITICAL CONFLICT IN MACHIAVELLI.

\begin{abstract}
This paper will examine whether it is possible to speak of a Machiavellian theory about the problem of raison d'État, standing against those interpretations that make a technocratic reading based on such issue. This concept will be considered from a tragic interpretive key, allowing us to explore the Machiavellian thought through the political conflict, which makes it impossible to reduce the Florentine's political thought to a simple calculation of means and ends.
\end{abstract}

Keywords: Machiavelli, Schmitt, conflict, raison d'État, tragedy.

\footnotetext{
* Universidad Nacional de Rosario, Argentina. Becaria en el programa Estímulo a las Vocaciones Científicas por el Consejo Interuniversitario Nacional. Correo electrónico: cecilia.mcd@gmail.com
} 
¡Tiempo descoyuntado! iQué maldita malicia, que haya nacido yo para poner justicia!

\author{
Shakespeare en boca de Hamlet. Acto I, escena V.
}

El PRESENTE TRABAJO TOMA COMO DISPARADOR la interpretación de Carl Schmitt en relación al pensamiento político de Nicolás Maquiavelo, en tanto considera que fue uno de los autores que permitió la apertura hacia una política desteologizada, absolutamente racional y técnica ${ }^{1}$, que se centra meramente en un cálculo de medios y fines. Tal interpretación se encuentra en su texto La dictadura en donde afirma, explícitamente, que en Maquiavelo "lo que domina es un interés puramente técnico". Dando crédito a la interpretación schmittiana, tendríamos que aceptar que la política en la reflexión del florentino pasaría a ser una técnica cuyo objeto es el Estado, es decir, la fundación, mantenimiento y expansión del mismo ${ }^{3}$. Esta interpretación se encausa a partir del análisis de un concepto problemá-

1 En el presente artículo consideraremos a los conceptos "técnico" y "racional" en el sentido que el propio Schmitt les atribuye en La dictadura, a saber, en tanto de ellos "se deriva la indiferencia frente al ulterior fin político" (p. 39). De este modo, creo que la tékhne política de la que habla el jurista es cualitativamente distinta a la práxis, en la que se vislumbra el verdadero sentido de lo político (i.e. donde aparece con toda su fuerza la distinción amigo-enemigo, sobre la base de un conflicto concreto) (Al respecto, vid. SchMiTT, Carl, "El concepto de lo político", en Carl Schmitt, teólogo de la política, FCE, México D. F., 2001, pp. 176-193). Lo que se busca dentro del marco de este accionar técnico y racional es una serie de reglas del buen funcionamiento del Estado, de donde se derive una ejecutividad pura, es decir, una obediencia inmediata y sin fricciones. Es por la unión de estos tres elementos (racionalismo, tecnicidad pura y ejecutividad) que, según Schmitt, se da comienzo al Estado moderno propiamente dicho; y tal comienzo se encuentra inaugurado, para el jurista, por Maquiavelo (Cfr. Sснмітт, Carl, La dictadura, Alianza, Madrid, 1985, pp. 36-44). Luego volveremos a este punto.

2 Sснмiтt, op. cit., p. 39. Esta interpretación corresponde, tal y como aclara Galli, a la obra de "juventud" del autor. En tal corpus, Maquiavelo aparece como "uno de los corresponsables originarios del verdadero estigma y del verdadero déficit de la Modernidad, es decir, de la transformación de la política en técnica, cuya culminación se verifica en el siglo XX" (GALLI, Carlo, Las mirada de Jano. Ensayos sobre Carl Schmitt, FCE, Buenos Aires, 2011, p. 99). Si bien más adelante en su obra, Schmitt introduce miradas alternativas respecto de la obra del florentino que lo colocan en un logar mucho más marginal (puede verse este giro en, por ejemplo en un texto de 1939 (18 años posterior a la interpretación de Maquiavelo que aquí analizamos en La dictadura), Schмiтt, Carl, "El concepto de lo político", en Carl Schmitt, teólogo de la política, FCE, México D. F., 2001, pp. 204-214. Si bien es interesante considerar estos cambios en vistas a realizar una cierta historia de las ideas analizando los cambios que ha tenido la interpretación schmittiana respecto de la obra maquiaveliana, este no es el propósito del presente escrito. En todo caso, se considerará a la interpretación que de Maquiavelo se propone en $L a$ dictadura de Schmitt como un disparador, en tanto se torna una de las posibles lecturas que incluso hoy en día pueden hacerse de la obra maquiaveliana; se considerará, asimismo, que tal interpretación es realizada por el jurista alemán en el momento en el que la obra del florentino adquiere una cierta centralidad en sus reflexiones. Los matices que propone el mismo Schmitt aparecen en el preciso momento en el que Maquiavelo pasa a ocupar un lugar mucho más relegado y, según creo por este mismo motivo, menos interesante, por lo que no es esta la etapa que se analizará. No obstante, remitimos nuevamente a GALLI, Carlo, op. cit., pp. 97-124, si es que al lector le interesa tener una lectura más panorámica de la interpretación schmittiana respecto de Maquiavelo.

3 Una lectura que puede apoyar tal interpretación que, aclaro ya desde el inicio, no es la que se seguirá en este trabajo, es la de Maiza Ozcoidi, I., "Acción y necesidad en el pensamiento político de Maquiavelo", Éndoxa: series filosóficas, $\mathrm{n}^{\circ}$ 28, 2011, p. 115-136. Asimismo podemos remitir a Prendes GuARdiola, Manuel, "La idea del príncipe en Maquiavelo y Gracián”, Mercurio Peruano, n 523, 2010, pp. 160-179. Estas posturas, 
tico que se relaciona con la lectura de la política en clave técnica, a saber, el de razón de Estado. Este concepto puede definirse, en términos generales, como un arte de cálculo, instrumentación y manejo de medios para el mantenimiento del Estado, i.e. un fin específico ${ }^{4}$. Considerado este concepto de tal manera y atribuyéndolo a Maquiavelo, no nos queda sino aceptar, como lo hizo Schmitt, que el florentino es el precursor por excelencia de un tipo de política tecnocrática, en donde el conflicto político queda por completo fuera del campo de análisis al constituir una mera excepción que no se circunscribe a las reglas instrumentadas para el mantenimiento del Estado. En otras palabras, el conflicto queda excluido e ignorado por ser una mera excepción a la regla.

En contraposición a esta lectura, en el presente trabajo se manejará la hipótesis de que si es lícito atribuir el problema de la razón de Estado a Maquiavelo, el mismo no puede ser interpretado como un mero problema técnico de medios y fines. En vistas a demostrarla se analizará no específicamente el concepto, sino la problemática de la razón de Estado (en el sentido ya aludido) que podría hallarse, ante todo, en su canónica obra El Príncipe. Allí encontraremos que si bien hay un fin claro que es la constitución y preservación del Estado italiano de la mano de un príncipe nuevo, no obstante, la obtención de tal fin no sólo es problemática en sí misma debido a las propias dudas del autor, sino que además los medios no pueden reducirse a meros instrumentos debido a que están atravesados por numerosos factores cuyas resultantes son absolutamente impredecibles. El caso maquiaveliano, considerado de esta manera, resulta mucho más complejo y no puede resolverse en un mero cálculo de medios en vistas a conseguir un fin específico. En este sentido, creo que es imposible restringir la propuesta del florentino a una ampliación del arte del Estado ${ }^{5}$, ya en boga en la Italia renacentista, sino que, tal y como sostiene Viroli, "El príncipe pretendía ser, a la par,

aunque recientes, no son, desde ya, novedosas respecto de la interpretación que históricamente se ha hecho de Maquiavelo como un técnico o un científico de la política. Una lectura similar puede encontrarse, por ejemplo, en Mantilla Pineda, Benigno, "Maquiavelo o el iniciador de la ciencia política moderna", Revista de estudios políticos, n 151, 1967, pp. 5-21; también en Maravall, José Antonio, La cultura del Barroco. Análisis de una estructura histórica, Ariel, Barcelona, 2012.

4 Sigo en esta definición a Viroli, Maurizio, De la política a la razón de Estado. La adquisición y transformación del lenguaje político (1250-1600), Akal, Madrid, 2009, pp. 35-44.

5 La problemática del Estado y del arte del Estado es sumamente compleja, por lo que se torna imposible revisarla seriamente en un artículo de las presentes características. En vistas a profundizar esta temática remitimos al ya citado Viroli; a Foucault, Michel, Seguridad, territorio, población, FCE, Buenos Aires, 2006, sobre todo a las clases del 25 de enero y del 1 de febrero de 1978, en donde concibe al modelo de soberanía a partir de tres caracteres que se derivan de la relación entre el príncipe y su principado en Maquiavelo; a SKINNER, Quentin, Los fundamentos del pensamiento político moderno, Tomo I: El Renacimiento, FCE, México D. F., 1985, en donde el autor propone una historia del concepto centrado no tanto en obras canónicas sino en la llamada "historia de las ideas", en vistas a construir un marco en el que situar aquéllas obras, marco en el que Maquiavelo adquiere una indiscutible relevancia no sólo en lo que concierte al concepto de Estado ( $c f r$ r. pp. 153-163 y 206-215) sino que también al de razón de Estado (cfr. pp. 276-283); a CAssirer, Ernst, El mito del Estado, FCE, México D. F., 1968, quien, si bien presenta una lectura alejada de la aquí presentada al considerar, por ejemplo, a El Príncipe como un libro técnico ( $c f r$. pp. 181-185), desarrolla un interesante análisis al considerar a Maquiavelo como el primer pensador que fijó su mirada en la nueva estructura política que constituía el Estado Nación en su tiempo (cfr. pp. 159-164); por último, para un análisis interesante aunque más amplio y situado en un estudio disciplinar divergente, a PoGgi, Gianfranco, El desarrollo del Estado Moderno, UNQ, Bernal, 1997, quien realiza una genealogía del concepto Estado desde una perspectiva sociológica en su evolución desde el Feudalismo hasta el siglo XX. 
crítica y apoyo a las teorías sobre el arte del Estado que circulaban por la Florencia de principios del siglo XV". Justamente el hecho de que Maquiavelo haya desarrollado una obra que puede enmarcarse dentro de la tradición republicana nos hace pensar que si bien abocó su pensamiento al arte del Estado, no podemos reducir toda la meditación maquiaveliana a una reflexión acerca del Estado o, llevándolo específicamente al tema que nos compete, de la razón de Estado7. Lo que nos interesa en relación al problema del Estado tal y como se concebía en la época de Maquiavelo es el hecho de que la reflexión que nuestro autor lleva a cabo en relación al arte del Estado, contradice constantemente el principio de justicia racional propio de la Antigüedad y del republicanismo humanista de su época ${ }^{8}$, poniendo en el centro de la cuestión al problema de la necesidad en política.

Vale aclarar, debido a que volveremos más tarde a esta cuestión, que tradicionalmente se ha concebido a la raison d'Etat como un conjunto de objetivos que legitiman el obrar político, es decir, los medios utilizados para alcanzar tal fin. Los objetivos, con sus posibles variaciones, son principalmente dos: la construcción y perpetuación del Estado, por un lado, y la expansión del mismo, por el otro. Puesto de una manera diferente, el poder político de un Estado tendría derecho a recurrir a los medios que fueran necesarios para forjar, mantener, perpetuar y expandir dicho Estado 9 . Ahora bien, dependiendo de la coyuntura histórica, social, económica, etc. las formas de mantener y expandir un Estado pueden variar significativamente. No necesariamente se tendrá que recurrir a medios violentos, por lo cual, en este caso, el soberano tendría la libertad de elegir entre una diversidad de caminos posibles, sobre todo si el momento histórico concreto en el que está ubicado no está atravesando un período, podríamos decir, excepcional de inestabilidad política. Pero así como el correr de los tiempos puede no requerir medios violentos para la perpetuación del Estado, así también la coyuntura puede demandar en tiempos de necesidad un accionar por parte del soberano que no se restrinja a lo que podría denominarse como un accionar ético o circunscripto a la moral en boga de tal época específica. Es por este motivo que Meinecke en su clásico estudio sobre la razón de Estado nos aclara, ya en la introducción, que tal concepto "se convierte así en el más profundo y más difícil de la necesidad política" ${ }^{\prime \prime}$.

6 Cfr. VIROLI, op. cit., p. 167.

7 Viroli incluso sostiene que, lejos de ser el padre espiritual de la idea de la política como razón de Estado, Maquiavelo es uno de los más firmes defensores de la política como el arte del buen gobierno de la república (Ibídem, p. 43). Una interpretación diversa a la propuesta por Viroli, puede verse en MeInEcKe, Friedrich, $L a$ idea de la razón de Estado en la Edad Moderna, Centro de Estudios Constitucionales, Madrid, 1983; y en Navarro Aznar, F., "El topos de la razón de Estado en su desarrollo ideológico”, Anales del derecho, n¹0, 1990.

8 En relación a la disputa moral con la Antigüedad, puede profundizarse el tema recurriendo al interesantísimo capítulo sobre Maquiavelo de Rinesi, Eduardo, Politica y tragedia. Hamlet, entre Maquiavelo y Hobbes, Colihue, Buenos Aires, pp. 33-43, en donde el autor postula que Maquiavelo propone un nuevo universo moral, abocado enteramente a valores políticos y no a valores cristianos (más adelante retomaremos esta interpretación). En cuanto a la disputa con el republicanismo de su época puede revisarse el ya citado texto de Viroli, sobre todo su capítulo dedicado exclusivamente a Maquiavelo (VIROLI, op. cit., pp. 161-212).

9 Cfr. Curzio, op. cit., pp. 30-31.

10 Meinecke, op. cit., p. 4. 
A lo largo del desarrollo veremos cuán extenso puede ser el problema que nos compete pero, asimismo, se intentará mostrar que el pensamiento maquiaveliano no puede reducirse a una reflexión sobre tal temática, sino que, en todo caso, su examen se desarrolla en torno al problema de la práxis política. Esto no quiere decir, debe aclararse, que Maquiavelo sea un mero teórico de la política "en general" como así tampoco una especie de "politólogo" de su época ${ }^{11}$. Si bien en el presente trabajo no se abordará específicamente la problemática de si el florentino fundó o no una ciencia de la política o si su pensamiento constituyó o no un pensamiento filosófico sistemático en relación a la política ${ }^{12}$, no obstante es preciso aclarar que la clave de lectura que se seguirá a lo largo del desarrollo es que Maquiavelo pensó a la política como atravesada por el conflicto. Un conflicto que, además, no es susceptible de resolución efectiva, por lo que se encuentra revestido de ropajes trágicos. Más adelante se profundizará sobre esta cuestión pero, por lo pronto, puede decirse que el hecho de que el florentino haya pensado a la política en términos de conflicto trágico hace que se haya volcado hacia una reflexión de la política de su época. Para nuestro autor, es preciso ir a la verità effetuale della cosa y, justamente gracias a esto, ha proporcionado una pauta para pensar a la política hoy día en esos mismos términos. En otras palabras, si bien Maquiavelo procuró una lectura situada de la política de su época, asimismo proporcionó algunas claves para pensar a la política, no tal vez de una manera estrictamente filosófica o sistemática, pero sí en términos de conflicto, tragedia y coyuntura $^{13}$.

El desarrollo se encuentra dividido en dos partes: en la primera se analizará el problema de la necesidad en política y la relación que ésta tiene con la coyuntura histórica determinada en la que tal necesidad se ubica. Asimismo veremos que la forma en que Maquiavelo había comprendido tanto a la necesidad como a la coyuntura, tiene particularidades importantes que determinarán la segunda parte del trabajo. Allí veremos el problema del conflicto en política y cómo éste adquiere, a partir del análisis de ciertos pares dilemáticos, un carácter absolutamente positivo y constructivo.

11 Una lectura de este tenor puede encontrarse, por ejemplo, en ToRRES VInDAS, Javier Antonio, “¿Qué es la política? Una lectura desde la teché política en Maquiavelo y Schmitt”, Revista de Filosofía de la Universidad de Costa Rica, XLVII (122), 2009, pp. 59-73.

12 En relación a estas temáticas recomiendo la lectura de FunEs, Ernesto, "Maquiavelo: el cartógrafo de la Modernidad", en Smola, Julia y Vommaro, Gabriel, Variaciones sobre Maquiavelo: a 500 años de El príncipe, UNGS, Los Polvorines, 2014.

13 Una vez más difiero con Maiza Ozcoidi, op. cit., p. 116, quien sostiene que Maquiavelo parece ser más un ciudadano romano que florentino. Skinner, en contraposición a esta autora, recupera la acción y reflexión política situada en la Florencia de su época (Skinner, Quentin, Maquiavelo, Alianza, Madrid, 2008). Asimismo, tal y como sostiene FunEs (op. cit., p. 39), Maquiavelo se nutre de los historiadores romanos no porque se sienta más allegado a la época que describen sino porque "busca la verdad efectiva de las cosas: cómo viven realmente los hombres, y no cómo deberían vivir". En este sentido, si bien Maquiavelo se sirve de los clásicos romanos no es por añoranza de su época o por un deseo de retornar a esa época, sino porque le sirve para leer su propia época que es, a fin de cuentas, en la que él mismo puede llevar a cabo su accionar político. 
LA TRAGEDIA DEL PRÍNCIPE. El PROBLEMA DE LA RAZÓN DE ESTADO Y SU RELACIÓN CON El CONFLICTO POLÍTICO EN MAQUIAVELO

\section{Necesidad y coyuntura: el problema de la doble moral}

Habiendo considerado, pues, todas las cosas que hasta ahora se dijeron y pensando para mi mismo si actualmente en Italia corrían tiempos que permitieran honrar a un nuevo príncipe, y si habia aqui una materia que diera ocasión a un príncipe prudente y virtuoso para introducir en ella la forma que le hiciese honor a él y bien a todos los hombres de aquella, me parece que son tantas las cosas que concurren en beneficio de un príncipe nuevo que no sé cuándo hubo un tiempo más propicio que este ${ }^{14}$.

El último capítulo de El príncipe se titula "Exhortación a apoderarse de Italia y a liberarla de las manos de los bárbaros". Su tiempo, tal y como sostiene Althusser ${ }^{15}$, imponía una solución a un problema concreto y coyuntural que consistía en la división en el interior de Italia, por un lado, y en las continuas invasiones de los extranjeros, por el otro. Las divisiones intestinas provocaban que las guerras no se libraran contra los verdaderos enemigos (los bárbaros: los franceses y españoles), sino contra sus propios compatriotas. Era necesario unir a Italia para enfrentar a los enemigos externos, por lo cual se tornaba forzosa la existencia de algo nuevo. Maquiavelo, tal y como marca Rebhorn, exhorta a este príncipe nuevo a enfrentarse al desafío de crear (i.e. de inaugurar creativamente) un Estado, y no ya a meramente heredarlo ${ }^{16}$. La ocasión era propicia y la materia estaba lista para recibir una nueva forma. Todo parecía estar preparado para que aparezca el príncipe nuevo que el florentino tanto clama y reclama en su obra. Ahora bien, ¿de dónde debe salir Italia y a dónde tiene que apuntar el accionar del príncipe nuevo? Y, por otro lado, ¿es esto posible? La primera pregunta se analizará en este apartado, la segunda en el siguiente.

La respuesta al primer interrogante podemos encontrarla en los Discursos. En el segundo capítulo del primer libro, el florentino relata el hipotético origen de la organización socio-política de los hombres basado en el azar. Para Maquiavelo no hay una ontología de la política, como en Aristóteles por ejemplo, como así tampoco un origen contractual, como propondrá el posterior iusnaturalismo. En otras palabras, el hombre no es político por naturaleza ni por contrato, sino que deviene político por la circunstancia fortuita de que un grupo de hombres decidió asociarse ${ }^{17}$. Es a partir de esta conjunción casual de hombres que, en vistas a defenderse, establecieron como jefes a los más fuertes y conocieron, a partir del accionar de tales regentes, lo que era bueno y malo, justo e injusto. Fue este conocimiento de justicia lo que los llevó a fundar gobiernos y a entrar, inevitablemente al conocido ciclo de Polibio:

14 Maquiavelo, Nicolás, El príncipe, Colihue, Buenos Aires, 2012, p. 136.

15 Cfr. Althusser, Louis, Maquiavelo y nosotros, Akal, Madrid, 2004, p. 50-52.

16 Cfr. Rebhorn, Wayne, "Machiavelli's Prince in the epic tradition", en Najemy, John (ed.), The Cambridge companion to Machiavelli, Cambridge University Press, Cambridge, 2010, pp. 80-82.

17 Cfr. Maquiavelo, Nicolás, Discursos sobre la primera década de Tito Livio, Losada, Buenos Aires, 2008, p. 56. 
Como dicen algunos que han escrito sobre las repúblicas, que en ellas hay tres gobiernos, llamados por ellos Monarquía, Aristocracia y Democracia, y que los que ordenan una ciudad deben inclinarse hacia uno de éstos, según les parece lo más apropiado. Algunos otros, más sabios según la opinión de muchos, opinan que los gobiernos son de seis clases: tres de ellos pésimos, los otros tres son buenos en sí mismos, pero tan fáciles de corromperse que también ellos llegan a ser perniciosos. Los buenos son los tres ya señalados arriba: los malos son los otros tres, de los cuales ellos dependen, y cada uno es tan semejante al que le es cercano que, entonces, fácilmente saltan del uno al otro ${ }^{18}$.

Inevitablemente los hombres se introducen en un círculo vicioso: al comienzo, una vez reunidos por la caprichosa fortuna, deciden establecer a un gobernante que sea el más justo y prudente debido a su indiscutible capacidad de liderazgo y gobierno pero, inevitablemente, ya sea porque el lugar que ocupa lo transforma en un gobernante sediento de poder o porque aquel que lo sucede no es tan perfecto, la monarquía se transforma en una tiranía que somete a la totalidad de sus súbditos. Ante esta situación, un grupo de hombres, los mejores y más sabios, se rebelan contra este gobierno tiránico y fundan una aristocracia, en la que la justicia vuelva a ser el faro que guía al gobierno. Pero nuevamente, por ser justamente un gobierno de hombres, tal aristocracia se terminará convirtiendo en una oligarquía, al transformarse los mejores (aristós) en una élite de ricos y poderosos. Ante esta nueva situación despótica, el pueblo no tendrá otra posibilidad que alzarse contra sus gobernantes y fundar una democracia, en la que el pueblo entero tenga voz y voto y, además, en donde ningún interés privado pueda imponerse sobre el general. Pero, irremediablemente, muerta la primera generación de hombres rebeldes al antiguo régimen, el espíritu popular no podrá sino convertirse en licencia, y dejará de respetarse al hombre privado, cometiendo ofensas contra cualquiera. Ante tal situación anárquica, no habrá otra solución que no sea imponer nuevamente un nuevo gobernante único que ordene la asociación política. Retornando así al inicio de la trayectoria, la serpiente no hace más que morder su propia cola y los hombres vuelven a caer en la trampa de este círculo vicioso de malos gobiernos ${ }^{19}$.

Esta exposición de las "buenas" y "malas" formas de gobierno nos muestra, sostiene el florentino, que todas son, en realidad, malas: las malas por tiránicas y las buenas porque duran poco. El ciclo polibiano no es sino un círculo vicioso de formas malas de gobierno que deben, por este motivo, ser evitadas a toda costa. Pero, nos dice Maquiavelo, "éste es el círculo en el cual girando todos los Estados se han gobernado y se gobiernan, pero raras veces vuelven a los mismos gobiernos, porque casi ningún Estado puede tener tan larga vida como para pasar muchas veces por estas mutaciones y quedar en pie" ${ }^{20}$. Este círculo produce, por lo tanto, no sólo inestabilidad continua en el interior del Estado, sino que además provoca que la duración del mismo sea exigua, ya que tanta inestabilidad no pue-

18 Maquiavelo, op. cit., p. 57.

19 Ibídem, pp. 57-59.

20 Ibídem, p. 59. 
de provocar sino que se socaven las bases de tal Estado y termine quedando en la ruina. El nuevo Estado Italiano que propugna el florentino debe, por lo tanto, salir de este círculo, es decir, no debe circunscribirse a ninguna de las tradicionales formas de gobierno.

El principado nuevo que describe Maquiavelo en El príncipe, en el que "un particular" ${ }^{21}$, un ciudadano cualquiera, puede convertirse en el nuevo soberano, parece intentar salirse del vicioso círculo polibiano. Esto se debe, justamente, al hecho de que nuestro autor intenta romper con la moral en boga que determina cuáles son las buenas y malas formas de gobierno. En el pensamiento del florentino, malo no es un gobierno que pueda llegar a ser cruel con sus habitantes, sino que es aquel que no perdura en el tiempo ${ }^{22}$. Es por este motivo que establecerá que "puesto que hay tanta distancia entre cómo se vive y cómo se debería vivir quien deja de lado lo que se hace por lo que se debería hacer aprende más bien su ruina que su propia preservación"23. El príncipe nuevo deberá, según Maquiavelo, actuar según la necesidad que la coyuntura demande, motivo por el cual muchas veces tendrá que saber salir de la moralidad en boga en vistas a un bien mayor. La salvación del alma, en este contexto, se encuentra por completo fuera de lugar ${ }^{24}$. Si el príncipe llegara a desinteresarse de los asuntos terrenales que son, a fin de cuentas, los que le competen, descuidaría su tarea e, inevitablemente, advendría el verdadero mal en política, a saber, la desintegración del Estado. Es justamente por esto que Skinner remarca que "un príncipe prudente debe guiarse ante todo por los dictados de la necesidad"25. El príncipe nuevo maquiaveliano debe saber entrar en el mal cuando la necesidad así lo dicta, debido a que tal necesidad responde al mantenimiento del Estado. Su accionar debe armonizar con la coyuntura histórica en la que está ubicado y, así, poder elegir lo que es mejor para el Estado. El príncipe, de este modo, debe ser capaz de sacrificar la salvación de su propia alma en pos de un fin superior, a saber, el mantenimiento y fortalecimiento del Estado. Este bien, así, constituye una nueva moral de carácter eminentemente política y terrenal. Es justamente por esto que puede decirse, retomando a Rinesi ${ }^{26}$, que ni la política es autónoma de la moral ni que simplemente el príncipe está obligado a actuar moralmente en determinados momentos, sino que la moral política es eminentemente distinta de la moral cristiana en boga. Aquí es donde radica el quid de la cuestión, ya que es precisamente esta diferencia la que impide que la reflexión maquiaveliana en torno a la necesidad y a la razón de Estado pueda reducirse a un mero cálculo de medios y fines. El príncipe se ve obligado, se ve exhortado, a elegir entre una moral cristiana, salvando así su alma pero

21 Maquiavelo, Nicolás, El príncipe, Colihue, Buenos Aires, 2012, p. 27.

22 A favor de esta interpretación, vid. Althusser, op. cit., pp. 71-79.

23 Maquiavelo, op. cit., p. 81.

24 Acerca del conflicto entre la salvación del alma y el bienestar del Estado, vid. BerLin, Isaiah, "La originalidad de Maquiavelo", en Contra la corriente. Ensayos de crítica cultural, FCE, México, 2000, pp. 85-143. Allí establece que no se elige "una esfera de medios (llamada política) como opuesta a una esfera de fines (llamada moral) [...]. El conflicto es entre dos moralidades, cristiana y pagana (o como algunos desean llamarla, estética), no entre esferas autónomas de moral y política" (pp. 115-116). El problema radica, como veremos más adelante, en la decisión que el príncipe pueda llevar a cabo al respecto.

25 SKINNER, op. cit., p. 57. 
llevando al Estado a su perdición, o una moral política, que condene su alma pero funde, mantenga y expanda al Estado. Para Maquiavelo, considerando la moral política, hay un fin último, un fin supremo, pero la obtención de tal fin jamás podría darse mediante una técnica o una receta, ya que la aceptación de tal moral por parte del príncipe no hace más que llevarlo a la condena del otro tipo de moral, la cristiana. Tal tipo de decisión jamás podría darse de manera mecánica. El príncipe, así, se halla atravesado intrínsecamente por esta decisión. A partir de lo cual reformulamos ahora la pregunta que nos hacíamos al principio de este apartado, ¿es capaz un hombre o, más específicamente, el hombre político por antonomasia, el príncipe, llevar a cabo esta decisión?

\section{Conflicto}

El príncipe, por lo que vimos, tiene que ser capaz de decidir entre indecidibles: o aceptar la verdadera moral cristiana que reina en su época, salvando su alma pero condenando la vida del Estado a su ruina o aceptar una nueva moralidad de tinte político en la que el bien mayor es el mantenimiento del Estado y en la que la salvación del alma no tiene lugar. Aquí se encuentra el contrapunto en relación al concepto de la razón de Estado que nos impide considerarlo como una problemática meramente técnica: si bien Maquiavelo se volcará sin dudas a la segunda opción (a la condena del príncipe en pos de la patria), tal elección no se reduce, no puede reducirse, a una mera elección racional donde reine un interés puramente técnico. Tal y como nos dice Berlin, "el hombre debe escoger" ${ }^{27}$ pero tal decisión no es, no puede ser sencilla. Maquiavelo mismo en sus Discursos nos había advertido que "los hombres toman ciertos caminos intermedios que son muy dañinos, porque no saben ser ni totalmente buenos ni del todo malos" ${ }^{28}$. Es imposible, por otro lado, porque la asociación política que el florentino está pensando contiene de base a la contradicción y al antagonismo que se presentan siempre en la vida de los hombres. En otras palabras, el hecho de que Maquiavelo no ignore que en el seno de toda sociedad se encuentra el conflicto impide que la persecución de un fin específico (como el mantenimiento del Estado) pueda conseguirse mediante la aplicación de una serie de reglas esquemáticas. Justamente encontraremos, a continuación, que nuestro autor piensa que el conflicto es esencialmente productivo, por lo que todo el accionar del príncipe tendrá que darse no a pesar del conflicto inherente al Estado que rige, sino que sólo gracias al hecho de que existe tal conflicto es posible que él pueda llevar cualquier acción a cabo. Asimismo veremos que tal conflictividad no se encuentra solamente en el interior del Estado sino, asimismo, en la constitución del hombre político por antonomasia, a saber, el príncipe. En uno y otro sentido la conflictividad es política pero, asimismo, trágica, ya que es imposible llegar a una resolución efectiva ${ }^{29}$.

26 RiNESI, op. cit., pp. 33-42.

27 Berlin, op. cit., p. 107.

28 Maquiavelo, Nicolás, Discursos sobre la primera década de Tito Livio, Losada, Buenos Aires, 2008, p. 123.

29 Creo que resulta interesante remarcar, en este punto, que un importante intérprete de Maquiavelo, como lo es Strauss, remarca que (en contraposición a lo que vamos a exponer a continuación) "en Maquiavelo encontramos 
El problema del conflicto en política puede verse con claridad en la teoría de los humores. Repetidas veces, tanto en los Discursos como en El Príncipe, Maquiavelo explica que hay dos humores que rigen la vida política: el de los grandes, que lo que quieren es dominar y poseer más, y el del pueblo, que lo único que desea es no ser dominado: "porque en cada ciudad se encuentran estos dos humores diversos; y de esto nace que el pueblo desea no ser mandado ni oprimido por los grandes, y los grandes desean mandar y oprimir al pueblo, y de estos dos apetitos diferentes nace en las ciudades uno de estos tres efectos: o principado, o libertad, o licencia"30. Vale aclarar: la ciudad está compuesta por hombres, pero, como tal, se encuentra unida y dividida por el mismo factor: en tanto hombres, todos están atravesados por el deseo de una falta o, en términos maquiavelianos, todos se encuentran afectados por los humores, aunque de modo distinto (los grandes quieren tener más, buscan dominar, pretenden oprimir; lo que el pueblo anhela es, afirma el florentino, mucho más noble y, para decirlo en pocas palabras, se trata de nada más y nada menos que ser libre, i.e. no ser dominado), lo cual no puede sino implicar una división en el seno de la ciudad. Pero, asimismo, es a partir de esta división, de este conflicto, que puede constituirse la unidad social. En otras palabras, lo social, un orden político determinado (principado o república), es el hecho empírico, el factum, que sólo puede ser descifrado mediante la división y el conflicto. En este contexto, no parece que resulte lícito hablar ni de un "deber ser" como así tampoco de un "ser" de los hombres y de la práctica política. Donde el conflicto prima, donde no es posible establecer una ontología acabada de la prácti-

comedias, parodias y sátiras, pero nada que nos recuerde la tragedia" (STRAuss, Leo, Meditación sobre Maquiavelo, Instituto de Estudios Políticos, Madrid, 1964, p. 356). Al respecto, podemos responder aludiendo a dos cuestiones: el reconocimiento del propio Maquiavelo como autor trágico (Cfr. Maquiavelo, Nicolás, "Carta del 21 de octubre de 1525 a Francesco Guicciardini”, en Cartas privadas de Nicolás Maquiavelo, Eudeba, Buenos Aires, 1979, p. 244, en donde firma su carta como "Niccolò Machiavelli. Historiador, cómico y trágico") por un lado, que es lo que le permite a Martinez sostener que "el drama le dio a Maquiavelo oportunidades no sólo para reflejar [mirroring] la sociedad civil de su época (que constituye una de las definiciones tradicionales de la función del teatro), sino que además para mostrar en escena una imagen del arte del Estado que él, más que nadie, era capaz de examinar" (Martinez, Ronald, "Comedian, tragedian: Machiavelli and traditions of Renaissance theater", en NaJEmy, John (ed.), The Cambridge companion to Machiavelli, Cambridge University Press, Cambridge, 2010, p. 206, la traducción me pertenece); por el otro, afirmar con Rinesi que "a partir del Renacimiento, esa fisura entre tragedia y vida social que advertíamos en el siglo de oro griego desaparece, y la propia vida social y política se vuelve trágica" (RINESI, op. cit., pp. 27-28, el subrayado el del autor). Es decir, lo trágico en la época que escribe Maquiavelo se aparta del rasgo pedagógico que era propio de las obras trágicas de la Antigüedad (y dejan de constituir "tragedias de los valores", las cuales tenían por objeto instruir al público respecto de lo que podía llegar a suceder si se dejaban dominar por la hybris), y pasa a "derramarse" sobre toda la sociedad. En otras palabras, si bien podemos reconocer que las antiguas tragedias tornan en derredor a un hombre individual (el héroe), y, en este sentido, se refieren a los conflictos propios de la culpa de su alma y no a los conflictos que aquejan a la vida social y política, no obstante, el acento está puesto en otro punto, ya que en el período que inaugura el Renacimiento ya no se tratará de tragedias de los valores (al respecto, recomiendo la lectura de Williams, Raymond, Tragedia moderna, Edhasa, Buenos Aires, 2014, pp. 35-51). Para responder a Strauss, entonces, podemos decir que a partir de la ruptura que se da con la concepción antigua de tragedia, aparece un nuevo tipo, a saber, la "tragedia de la acción" que consiste, justamente, en el hecho de que aún cuando se intente optar por un sistema de valores, no obstante, éste no bastará para lograr los fines esperados y, por ende, el conflicto permanecerá (Cfr. Rinesi, op. cit., pp. 33-67). Puede, incluso, redoblarse la apuesta, y sostener con Torres que "no sólo no hay un fin único en términos valorativos, sino también que en realidad no hay un fin (temporal) en cuanto tal, porque ese desacuerdo fundamental se proyecta hacia el pasado y el futuro, y hace de la conflictividad la constante irresuelta" (TorRes, Sebastián, Vida y tiempo de la república. Contingencia y conflicto político en Maquiavelo, UNGS-UNC, Los Polvorines, 2013, p. 312).

30 Maquiavelo, Nicolás, El príncipe, Colihue, Buenos Aires, 2012, p. 49. 
ca política, tampoco podemos remitir a una transparente antropología positiva o negativa ${ }^{31}$. Tal y como sostiene Torres, lo que en Maquiavelo prima y lo que constituye, de esta forma, su punto de partida problemático, es "la imposibilidad del hombre de mantenerse en (y de atribuirle) un modo de conducta determinado"32. El florentino, así, se aparta tanto del pesimismo como del optimismo político, ubicándose dentro del terreno de un realismo político en el que la lucha entre distintas variables conflictivas se torna patente. En este sentido, tal y como Lukács atribuye al realismo que aquí indicamos como propio de Maquiavelo, el mundo externo no aparece como una mera objetividad muerta que determina fatalmente la vida de los hombres, sino que se encuentra en la más íntima e indisoluble interacción con la práctica humana ${ }^{33}$. Aquí entendemos al realismo maquiaveliano, entonces, en tanto constituye una concepción conflictivista (y no, por ende, armónica) de lo político, en el sentido de que "el conflicto es siempre, en última instancia, constitutivo del espacio político y ningún ordenamiento institucional consigue contenerlo y superarlo de una vez para siempre" ${ }^{34}$. La forma en que el poder medie el conflicto entre los humores de los grandes y del pueblo, determinará la constitución simbólica de lo social, afirmándose, así, en una forma institucional específica (República o Principado), o acabará por anularse a sí misma en la licencia.

31 Podemos, nuevamente, hacer una referencia contra Schmitt quien, en numerosas ocasiones, ubica a Maquiavelo como un pensador que parte de una antropología negativa. Al respecto, remitimos al ya citado texto de Schmitt en la primer nota del presente artículo ("El concepto de lo político"), como así también a su "Teología política I", en Carl Schmitt, teólogo de la política, FCE, México D. F., 2001, pp. 19-62. Al respecto, puede revisarse, nuevamente, el ya citado libro de GALli, op. cit., pp. 109-111. En contra de una antropología maquiaveliana de la que se podría deducir posteriormente el resto de su filosofía puede revisarse, aparte del texto de Torres que se citará a continuación, el artículo de Vernazza, Diego, "La política en la ciudad dividida", en Cuadernos Filosóficos, segunda época, $n^{\circ} 11,2014$, pp. 90-93.

32 TORRES, op. cit., p. 74.

33 Cfr. LuKÁcs, Georg, Materiales sobre el realismo, Grijalbo, Barcelona, 1977, p. 192.

34 Portinario, Pier Paolo, El realismo político, Nueva Visión, Buenos Aires, 2007, p. 32. Portinaro concibe que al realismo político pueden agregarse, además de la concepción conflictivista de lo político, una concepción estratégica de la política (cuya acción se centra, no en torno a valores absolutos, sino en el éxito) y una concepción técnica del Estado (en tanto éste es visto como un conjunto de relaciones de fuerza o como instrumento de imposición de un orden). Creo que esta concepción de "técnica" es distinta a la presentada por Schmitt (Cfr. nota 1) en tanto no pretende erradicar al conflicto justamente porque no es posible hacerlo. Tal y como remarca un poco más adelante, "el realismo se encuentra perpetuamente en vilo entre la carencia y el exceso: la estrategia de autoconservación a menudo corre el riesgo de resultar débil en un mundo en continuo movimiento, donde para mantenerse es preciso crecer. Pero la estrategia de autoafirmación resulta intrínsecamente desestabilizadora, orientada como está a la dominación y a la hybris. Esta ambivalencia se encuentra en el código genético del realismo político" (p. 33) (es notable aquí la resonancia maquiaveliana del pasaje que reza "es necesario juzgar la verdad, ya que estando siempre las cosas humanas en movimiento, suben o bajan" [MAQUiAVELo, Nicolás, Discursos sobre la primera década de Tito Livio, Losada, Buenos Aires, 2008, p. 206]). Otra cuestión que debe ser remarcada del texto de Portinaro es que lee tanto a Maquiavelo como a Schmitt en clave realista (Cfr. p. 31), por lo que la concepción que tienen uno y otro de lo político y su práctica estaría basado en el conflicto aunque, la concepción que de conflicto tienen estos autores es diversa. En otras palabras, Si bien Schmitt convierte al conflicto en lo propio de lo político y su práctica (la política), su lectura del conflicto a partir del par amigoenemigo nos lleva a interpretarlo como un caos al cual debe darse una respuesta concreta, eliminando a todo lo que se oponga a semejante resolución (Cfr. Sснмітт, Carl, "El concepto de lo político", en Carl Schmitt, teólogo de la política, FCE, México D. F., 2001, pp. 176-186). Tal y como sostiene García Alonso, "la primera decisión en política es la opción entre caos y orden" (GARCía Alonso, Marta, "Carl Schmitt o la imposibilidad de una política secularizada", Isegoría, n³2, 2005, p. 240). En contraposición a esta interpretación del conflicto, encontramos que en Maquiavelo tal noción asume un matiz enteramente positivo, en tanto resulta el puntapié inicial para establecer las mejores leyes. 
El soberano, entonces, debe enfrentarse necesariamente al conflicto que es inherente a la ciudad; conflicto que, recordemos, tiene un matiz absolutamente positivo no sólo porque es el motor que pone en marcha el funcionamiento de lo social, sino que también porque es aquello de donde surgen las mejores leyes que permiten, a su vez, que el principado (o la república) sea feliz ${ }^{35}$. Pero este soberano, sabemos, no sólo debe enfrentarse a los humores que rigen la vida en la ciudad, sino también con otros factores que lo constituyen en su propia especificidad. Por un lado, encontramos al par virtù-fortuna, entendiendo a ésta última como aquella fuerza azarosa irrefrenable (encarnada ya sea en una condición forzosa, ya en una situación eventual) que afecta indefectiblemente la mitad de la vida de los hombres, y a la primera como una especie de prudencia que permite a quien la tiene manejar los vaivenes de la fortuna en su coyuntura específica, con una disposición de ánimo tal que permite ordenar las vicisitudes de la historia de modo que la adversidad no sea capaz de golpear con toda su fuerza. La virtù, es descripta, entonces, en un doble sentido: por un lado, se trata de una inteligencia práctica (que podría emparentarse con el clásico significado de phrónesis) que permite, a quien la tiene, observar las circunstancias y medir las posibles consecuencias; pero, al mismo tiempo, la virtù parece alejarse de este primer sentido para ubicarse en sus antípodas e identificarse, aludiendo así a un segundo sentido, con una actitud enteramente irreverente ante la fortuna, como aquello que permite hacerle frente actuando de manera valerosa sin reparar en el frío cálculo del primer sentido ${ }^{36}$. La virtù, entonces, no es reductible a la virtud clásica, sino que se trata de una virtù política, a partir de la cual el príncipe puede aparentar ser moralmente virtuoso cuando el devenir de la coyuntura así lo requiera. Se trata de parecer serlo y no efectivamente serlo ${ }^{37}$, ya que, de otro modo, aquélla virtud moral podría atarlo a consecuencias nefastas para el mantenimiento del Estado. Ahora bien, tal y como sostiene Rinesi ${ }^{38}$, virtù y fortuna son como los dos extremos de un péndulo que sigue su trayectoria sin cesar, el cual parece detenerse en un polo para después seguir su camino hacia el otro. Maquiavelo aparenta, en algunos capítulos de El príncipe, tener esperanzas en el príncipe virtuoso, en que será capaz de alcanzar su meta, logrará unificar Italia y arrebatar el poder que habían obtenido los bárbaros. Es más, el florentino declara ${ }^{39}$ que la fortuna sólo rige la mitad de las acciones humanas, por lo que podríamos deducir que la otra mitad depende del accionar humano y, más específicamente, del accionar virtuoso del príncipe que podría, en esta lucha, ganarle la pulseada a la fortuna. No obstante, es preciso remarcar que el príncipe es capaz de ocuparse solamente de la "otra mitad" que la fortuna deja a su arbitrio, por lo que carece de garantía alguna de que sus decisiones y acciones lleguen a buen puerto. En otras palabras, aunque el príncipe sea virtuoso y sea capaz de actuar según la exigencia de la necesidad y las circunstancias, aún así puede fracasar. La fortuna, en este sentido, no es algo que

35 Cfr. Maquiavelo, op. cit., p. 56.

36 Sigo en esta interpretación a CostA, Ivana, "La oposición virtù-fortuna vista desde sus raíces griegas", Cuadernos Filosóficos, segunda época, n 11, 2014, pp. 52-63.

37 Cfr. Maquiavelo, op. cit., lib. I, cap. XXV. Maquiavelo, Nicolás, El príncipe, Colihue, Buenos Aires, 2012, cap. $\mathrm{XV}$.

38 Cfr. RinEsi, op. cit., cap. 1.

39 Cfr. Maquiavelo, op. cit., pp. 131-132, cap. XXV. 
venga 'de afuera', sino que es parte constitutiva de la acción política ya que, tal y como sostiene Torres, "la contingencia está inscripta en los mismos elementos que componen la acción" ${ }^{\prime 4}$. No hay, no puede haber, seguridad en que el Estado sea efectivamente fundado, mantenido y expandido, aún cuando el príncipe actúe y elija todo lo virtuosamente posible e, incluso, se atenga solamente a la moral política que Maquiavelo tanto clama. El soberano, así, se encuentra inmerso en una tensión extrema que, veremos a continuación, lo constituye como tal ${ }^{41}$.

El soberano también se haya atravesado, en su propia especificidad, por otro par: humanidad-animalidad. Al respecto, Maquiavelo observa que "hay dos modos de combatir: uno con las leyes y el otro con la fuerza. El primero es propio del hombre; el segundo, de las bestias; [...] para un príncipe es necesario saber bien emplear a la bestia y al hombre" ${ }^{\$ 2}$. Las leyes son el modo de combate propio de los hombres, son las que hacen que los habitantes de una ciudad se hagan buenos y son la garantía de una república o un principado feliz ${ }^{43}$. El problema es que no siempre el príncipe puede restringirse a las leyes, sea porque la necesidad llama, sea porque ha sucedido algo que no está contemplado en ellas. Es en ese momento en el que debe recurrir a su segunda naturaleza animal y hacer uso de la violencia. No obstante, la bestia que el príncipe debe saber usar no se reduce sólo a la fuerza bruta (propia del león, nos dice el florentino), sino que además debe ser astuto como un zorro, al punto en que se vuelve conveniente que tenga una cierta astucia afortunada ${ }^{44}$. Algo interesante aquí, y que resulta necesario aclarar para comprender más cabalmente

40 Torres, op. cit., p. 79.

41 Creo que aquí hay un costado interesante para analizar con más profundidad. Me refiero a que, según interpreto esta cuestión, la indecisión que parece ser propia del príncipe maquiaveliano comienza una ruptura (que luego se radicalizará en la Modernidad) entre la ley y el saber. Lo significativo aquí es que justamente tal ruptura es la que dará lugar, según Lefort, a las democracias modernas, en las que el lugar de poder (antiguamente ocupado personalmente por el rey) quedará vacío por no estar encarnado por nadie. Concebido de este modo, el poder democrático moderno se torna en una pura instancia simbólica que no está condensada ni en la ley ni en el saber. En las democracias modernas convive, por ese motivo, una sociedad privada de una unidad sustancial, ya que no puede haber una materialización concreta ni de Otro ni del Uno. De este modo, nos dice el autor, "la delimitación de la actividad propiamente política tiene por efecto instituir una escena sobre la cual el conflicto se representa a la vista de todos [...] como necesaria, irreductible, legítima (p. 38, el subrayado es del autor) (Cfr. Lefort, Claude, ¿Permanece lo teológico-politico?, La Hachette, Buenos Aires, 1988, pp. 33-38 y 68-75). Creo que, leído en la clave que se presenta en este artículo, Maquiavelo constituye un precedente indiscutible para la comprensión de la teoría política moderna, aunque en un sentido distinto al que le atribuye Schmitt. Para un tratamiento más exhaustivo del tema de la democracia considerada en este sentido y como opuesta a la propuesta schmittiana, puede revisarse mi artículo "Democracia y conflicto: la tragedia irresoluble del soberano", en Bertolacci, Franco (comp.) Memorias del XI Congreso Nacional y IV Congreso Internacional sobre Democracia: Congreso sobre democracia, entre el malestar y la innovación: los nuevos retos para la democracia en América Latina, UNR editora, Rosario, 2014, pp. 239-250.

42 Maquiavelo, op. cit., p. 92.

43 Cfr. Maquiavelo, Nicolás, Discursos sobre la primera década de Tito Livio, Losada, Buenos Aires, 2008, pp. $56,62,108,162-164$, etc.

44 Cfr. Maquiavelo, Nicolás, El príncipe, Colihue, Buenos Aires, 2012, p. 49. Esta astucia afortunada, indica González en su lectura de los capítulos de El príncipe, es justamente aquella de la que el soberano deberá valerse para ganar el favor del pueblo, satisfaciendo su apetito de no ser dominado y ganando su lealtad. $C f r$. GonzÁlez, Horacio, "Comentarios a los capítulos de El príncipe", en Maquiavelo,Nicolás, El príncipe, Colihue, Buenos Aires, 2012, pp. 192-201. 
la novedad y complejidad del pensamiento maquiaveliano, es que nuestro autor está rompiendo una vez más con la tradicional ontología política y, en particular, con la aristotélica, reinante en su época. Aristóteles había dejado sentado que el hombre es un animal político por naturaleza y que aquellos que, por naturaleza, viven sin ciudad (pólis), son de un rango inferior (animales) o superior (dioses) respecto del hombre ${ }^{45}$. Cicerón, por su parte, había establecido en su De officiis que el hombre tenía dos formas de injuriar o hacer el mal: o con la violencia o con el engaño. Este tipo de accionar no es propio del hombre, sino que pertenece a las bestias, siendo la violencia la característica propia del león y el engaño la del zorro. El hombre, al ser violento o engañar, no sólo estaba ejerciendo el mal, sino que además rompía con su propia cualidad de hombre, rebajándose a la condición animal y desprestigiando la dignidad humana ${ }^{46}$. Maquiavelo rompe con esta estructura estableciendo que es necesario que el hombre político por antonomasia, el príncipe, deba recurrir a estratagemas y estrategias propias de los animales, sin que por ello la ciudad se convierta en una comunidad de animales aunque, inevitablemente, se desdibuje la propia naturaleza humana confundiéndola con la animal ${ }^{47}$. Recordemos, al respecto, que el florentino sostiene que el uso de violencia (recurso propio de los animales) no necesariamente genera más violencia sino que, por el contrario, si tal recurso es bien usado, puede provocar la restauración del orden y la paz en la ciudad, de modo que puedan volver a implementarse las leyes (recurso propio de los hombres) ${ }^{48}$.

El soberano, así, se haya atravesado por múltiples tensiones: los grandes y el pueblo, virtù y fortuna, virtù política y virtud moral, bestia y hombre. Es a partir del conflicto entre estos extremos que el príncipe se constituye como tal. Ahora bien, justamente por el hecho de que el príncipe sea el sujeto político por excelencia, está condenado a actuar y llevar a cabo decisiones que le permitan resolver problemas coyunturales específicos. En vistas a resolver este problema, Maquiavelo intenta ayudar al príncipe nuevo recurriendo a las enseñanzas de la historia, pretendiendo, de alguna manera, establecer un entreverado compendio de acción, del cual el nuevo sujeto político sería capaz de valerse. No obstante, tal y como nos dice González, "Maquiavelo no escribe el Qué hacer sino un manual absurdo sobre la imposibilidad de que haya leyes o regularidades que inspiren la certeza en el hacer"49. En otras palabras: no hay reglas, no puede haberlas. Maquiavelo, de alguna manera, ya nos había advertido esto al decir que no hay que pensar las cosas como debieran ser, sino como efectivamente son, es decir, yendo a la verità effettuale della cosa ${ }^{50}$.

45 Cfr. Aristóteles, Pol. 1253a1-5.

46 Cfr. Cícerón, Marco Tulio, De Officiis, Macmillan, Londres, I, 13, 41. Para un análisis más pormenorizado de la relectura maquiaveliana de Cicerón vid. SkINNER, op. cit., sobre todo el cap. II.

47 Recordamos, aludiendo al apartado anterior, que esta no es la única forma en la que Maquiavelo rompe con la tradición aristotélica. En contraposición al estagirita, el florentino remite a un comienzo azaroso de la comunidad política. La política misma, entonces, es hija de la fortuna (vid. Althusser, op. cit., sobre todo cap. 2).

48 Cfr. Maquiavelo, op. cit., cap. VIII. En relación al problema de la economía de la violencia recomendamos una lectura del ya clásico texto de Wolin, Sheldon, Política y perspectiva, Amorrortu, Buenos Aires, 1974, cap. 7.

49 GonZÁLEZ, op. cit., p. 190.

50 Cfr. Maquiavelo, op. cit., p. 81. 
Esto no significa que debamos ir a una supuesta verdad empírica, fotográfica, meramente descriptiva de la realidad, sino que debemos pensar la coyuntura histórica en su devenir, en su acontecer cambiante ${ }^{51}$. Se trata de una mirada que no naturaliza lo dado, sino que muestra la historia en su puro acontecer, en tanto que es capaz de producir efectos que constituyen, de este modo, una verdad histórica a la cual podemos remitir justamente porque si bien todo en el orden de la naturaleza y de los hombres sube y baja, no obstante siempre hay una misma cantidad de bien y de mal en el mundo ${ }^{52}$. Es en este contexto en el cual el príncipe debe llevar a cabo sus decisiones, su accionar. Pero, justamente por ser este el contexto, nunca tendrá una garantía de que sus acciones sean las correctas. La existencia del príncipe, justamente por estar atravesada por conflictos irresolubles, es una existencia trágica y la política misma, de este modo, se convierte en tragedia. Si esto es así, el resultado no es la armonía, sino una desarmonía constante en donde reina un laberinto de paradojas. La decisión, de este modo, se subsume asimismo en este círculo paradojal, de modo tal que su propia existencia se torna imposible ya que cualquier decisión se convierte, desde cualquier punto de vista, en un indecidible.

\section{Reflexiones finales}

Al comienzo de este trabajo se tomó como disparador la acusación schmittiana de que el pensamiento político maquiaveliano no era más que el precursor de un tipo de política tecnocrática de simple cálculo de medios y fines. El jurista alemán parece haber leído a $E l$ príncipe como un mero manual, en el que el florentino habría intentado indicarle al príncipe cómo proceder, considerando que, habiendo un fin claro y específico, todo accionar debía estar guiado y medido por ese fin. Explícitamente Schmitt había interpretado que

En los asuntos políticos y diplomáticos, lo que más le preocupa [a Maquiavelo] son las cuestiones de cómo puede alcanzarse un determinado éxito, como se «hace» algo [...]. De la «tecnicidad» absoluta se deriva la indiferencia frente al ulterior fin politico, del mismo modo que un ingeniero puede sentir un interés técnico por la fabricación de una cosa, sin que tenga que sentir el menor interés propio por el ulterior fin a que esté destinada la cosa a fabricar. Lo que se plantea como problema es algún resultado político ${ }^{53}$.

De esta tecnicidad, nos dirá Schmitt, se deriva inevitablemente un racionalismo extremo en el que, una vez determinado el resultado político a alcanzar, el cálculo de los medios para llegar a él se puede dar de una manera absolutamente racional. A estos dos

51 En relación a la problemática de la verità effettuale della cosa, son recomendables en vistas a su profundización las lecturas de Costa, Ivana, "Introducción a El Príncipe", en Maquiavelo, Nicolás, El Príncipe, Colihue, Buenos Aires, 2012; y Rinesi, Eduardo, "Efectualidad, pasiones y virtù", en Smola, Julia y Vommaro, Gabriel, Variaciones sobre Maquiavelo: a 500 años de El Príncipe, UNGS, Los Polvorines, 2014.

52 Cfr. Maquiavelo, Nicolás, Discursos sobre la primera década de Tito Livio, Losada, Buenos Aires, 2008, lib. II, Proemio. En relación a esta cuestión sobre la relación entre variación y permanencia histórica en Maquiavelo, puede revisarse el ya citado artículo de Vernazza, op. cit., pp. 87-90.

53 Sснміт, op. cit., p. 39. 
elementos deben sumárseles también la ejecutividad, ya que los medios que se utilicen deben ser llevados a cabo sin ningún tipo de fricción. La existencia de estos tres elementos (tecnicidad, racionalidad y ejecutividad) en una teoría política es, para el jurista, el señalador del comienzo del Estado moderno y, con él, de la teoría de la razón de Estado, entendida como una máxima sociológico-práctica que se deriva de las necesidades del poder político y, en particular, de su fundación, mantenimiento y ampliación ${ }^{54}$.

En esta interpretación encontramos, entonces, a un Maquiavelo absolutamente técnico. El problema de la necesidad se reduciría a un conjunto de reglas que se utilizarían y cambiarían con el transcurso de la coyuntura, de modo que pueda actuarse de manera absolutamente racional y sin fricciones. Ahora bien, algo que Schmitt parece estar olvidando es que cuando el florentino habla del problema de la necesidad la concibe en tanto estrechamente ligada a otro concepto igualmente fundamental en el pensamiento maquiaveliano, a saber, la verità effettuale della cosa. Este concepto, tal y como vimos, no hace referencia a una verdad empírica meramente descriptiva de la coyuntura, sino al acontecer histórico en su devenir. Actuar según la necesidad y yendo a la verità effettuale della cosa no significa acomodar una serie de reglas a una supuesta realidad empírica y dada para que la obtención de un fin pueda darse sin fricciones, sino que significa que el sujeto político virtuoso comprenda que parte de su accionar depende de la fortuna entendida no como algo que viene indefectiblemente 'desde afuera', sino en tanto que compone la acción política misma. De este modo, el príncipe en tanto su accionar se encuentra constituido por virtù y por fortuna, no tiene garantía alguna de que será exitoso. No puede haber, en este contexto, un accionar sin obstáculos en el que todo es medible y que conduce indefectiblemente a un fin específico. Por otro lado, tal y como vimos, Maquiavelo inaugura un nuevo tipo de moralidad que entra en contradicción con la moral de su época, de modo que la salvación del alma del príncipe queda condenada en pos de la salvación del Estado. Sumado a lo anterior, no puede suponerse que las decisiones que el soberano lleve a cabo puedan darse en un plano de tecnicidad, racionalidad y ejecutividad. La razón de Estado en Maquiavelo, si es lícito atribuirle una teorización al respecto, no puede concebirse, tal y como pretendía Schmitt, como la puerta de entrada a un tipo de política tecnocrática. Si bien el estudio de la raison d'Etat se encuentra atravesado por la cuestión de la necesidad (a saber, la fundación, mantenimiento y expansión del Estado italiano), no se trata de una problemática transparente y medible. No sólo el concepto de necesidad no es tan sencillo como el pensador alemán había supuesto, sino que además, el sujeto político por antonomasia, quien debe llevar a cabo las decisiones, es incapaz de actuar teniendo la garantía de que todo resultará bien, debido a que las contradicciones y las paradojas reinan en su interior. Al respecto, ya hemos visto que el conflicto interno que experimenta y constituye al príncipe se debe, tanto al par dilemático moral al que se encuentra sometido (una moral de tipo cristiana y una más bien política) como a la incertidumbre ante los resultados impredecibles de sus decisiones (incertidumbre que surge como corolario de aquél dilema y

54 Cfr. Sснмітт, op. cit., pp. 39-44. 
del conflicto propio de la ciudad). En cierto punto, uno podría, en tanto lector, creer que el príncipe tiene todas las herramientas para triunfar y unificar a Italia gracias a su virtù y a su astucia afortunada, consecuencia de su constitución dual de hombre y animal. Pero incluso a pesar de estar munido de ellas, el péndulo de la historia parece siempre recaer en el otro costado, no sólo porque la mala fortuna siempre se encuentra al acecho, sino porque, además, las opciones ante las que se encuentra el príncipe son, en realidad, problemáticas y conflictivas en sí mismas, debido a que en su decisión se juega la salvación de la ciudad o la de su alma.

Esto no quiere decir que el príncipe sea incapaz de actuar. Todo lo contrario: el hecho de que él sea el sujeto político por antonomasia lo arroja a este mundo en el que se encuentra forzado a actuar. Pero aquello sobre lo que tendría que decidir porque, según Schmitt, esto lo definiría en tanto soberano, i.e. la excepción ${ }^{55}$, se convierte, asimismo, en un indecidible. La decisión que tanto ansía el jurista alemán no podría tener lugar en este pluriverso político trágico en el que la excepción, aquello que es incapaz de subsumirse a lógica alguna, aquello que no encaja en norma ni ley alguna, no tiene encarnadura, convirtiéndose ella misma en la regla.*

\section{Bibliografía}

Althusser, Louis, Maquiavelo y nosotros, Akal, Madrid, 2004.

Aristóteles, Política, trad. E. Sinnott, Losada, Buenos Aires, 2007.

Berlin, Isaiah, "La originalidad de Maquiavelo", en Contra la corriente. Ensayos de crítica cultural, FCE, México, 2000, pp. 85-143.

Cassirer, Ernst, El mito del Estado, FCE, México D. F., 1968.

Ciceron, Marco Tulio, De officiis, trad. W. Miller, Macmillan, Londres, 1913.

Costa, Ivana, "Introducción a El Príncipe", en Maquiavelo, Nicolás, El Príncipe, Colihue, Buenos Aires, 2012, pp. V-LXX.

, "La oposición virtù-fortuna vista desde sus raíces griegas", Cuadernos Filosóficos, segunda época, n 11, 2014, pp. 51-64.

Curzio, L., "La forja de un concepto: la razón de Estado", Estudios politicos, octava época, n², 2004, pp. 27-71.

55 Cfr. Schmitt, Carl, "Teología política I”, en Carl Schmitt, teólogo de la política, FCE, México D. F., 2001, p. 23.

* Artículo recibido: $1^{\circ}$ de mayo de 2015. Aceptado: 25 de julio de 2015. 